\title{
El legado de Francisco Morazán en centroamérica: los imaginarios del héroe unionista y su herencia histórica
}

\author{
Dr. Jorge Alberto Amaya Banegas \\ Docente de Historia de la Universidad Pedagógica \\ Nacional Francisco Morazán, UPNFM \\ jorgealbertoamaya@gmail.com
}

DOI: http://dx.doi.org/10.5377/koot.v0i8.5869

URI: http://hdl.handle.net/11298/383

\section{Resumen}

Este modesto artículo intentará exponer cuáles fueron algunos de los alcances de dicha Reforma en la construcción de ciertos imaginarios de nación, y en especial, intentará describir cómo los reformadores se dieron a la tarea de construir un nacionalismo basado en la creación del "Panteón de los Héroes Nacionales", exaltando preferentemente a Francisco Morazán como el principal prócer reinante de ese "Panteón sagrado". Asimismo, presentará algunos tópicos que a juicio del autor son herencias o legados fundamentales del genio de Morazán para la región centroamericana.

Palabras clave: Historia, identidad, cultura, localidad, nacionalismo, patriotismo, imaginario.

\begin{abstract}
This modest article will attempt to explain what some of the scopes of the reform in the construction of certain imaginaries of the nation were, and especially, it will attempt to describe how the reformers accomplished the task of building nationalism based on the creation of the "Pantheon of the National Heroes," preferentially praising Francisco Morazán as the main founding father of that "Sacred Pantheon." Moreover, according to the opinion of the author, some topics will be developed as the inheritances or fundamental legacies of the genius of Morazán for the Central American region.
\end{abstract}

Keywords: History, identity, culture, town, nationalism, patriotism, imaginary 


\section{Introducción}

Fue durante el proceso de las Reforma Liberales (más o menos desde 1870 hasta 1930), que en Centroamérica -especialmente en Guatemala, El Salvador y Honduras- en que se reforzaron los cimientos de la construcción del Estadonación en el istmo.

De este modo, analizaremos en parte la formación de la nación en Honduras y el resto de países centroamericanos y la invención de tradiciones a partir de la sacralización de la figura del General Francisco Morazán ${ }^{1}$. En particular, nos interesa conocer cómo se construyó en el imaginario colectivo una tradición histórica común, cómo se "inventó" un imaginario nacional y cómo se creó y "sacralizó" el Panteón de los héroes nacionales a partir de la figura de Morazán.

Conceptualmente, en este caso recurrimos al término "invención de tradiciones" en la acepción que le otorgaron Eric Hobsbawm y Terence Ranger, para quienes la "invención de tradiciones" supone tres tipos básicos de procesos: los que simbolizan cohesión social o pertenencia a grupos reales o artificiales; los que legitiman instituciones o relaciones de autoridad y los que priorizan la socialización, la enseñanza de creencias y sistemas de valores ${ }^{2}$.

En el caso de Honduras, con la "invención de la tradición" del culto al "Panteón de los héroes" y la exaltación de la figura de Morazán, basada en su gesta heroica de la República Federal y sus victorias en las batallas contra los conservadores, se difundieron por tanto nuevos sistemas de valores, derechos y obligaciones entre los hondureños del siglo XIX, como fueron el patriotismo y la lealtad a la nación. Además, Morazán y otros imaginarios nacionales fueron usados por las élites liberales de la época para construir una tradición que permitiera dar un sentido de unidad nacional y nacionalismo.

${ }^{1}$ José Francisco Morazán Quesada nació en Tegucigalpa en 1792 y murió fusilado en San José de Costa Rica en 1842. Fue un genial militar en el campo de batalla, lo que le llevó a ocupar la presidencia de la República Federal de Centroamérica entre 1830 y 1838. Antes, había sido Jefe de Estado de Honduras en 1827. Instruido en la ideología liberal por su pariente Dionisio de Herrera, impulsó como presidente federal una serie de reformas conducentes a instaurar un Estado liberal según el modelo aplicado por los revolucionarios franceses y especialmente por los estadounidenses. Una vez disuelta la República Federal, salió rumbo a Panamá y Perú; volvió a Centroamérica en 1842, asentándose en Costa Rica, donde fue electo Jefe de Estado tras la renuncia de Braulio Carrillo, sin embargo, una rebelión desestabilizó su régimen. Capturado tras una traición de algunos allegados, fue fusilado sin previo juicio -irónicamente- el 15 de septiembre de 1842. Fue autor de Apuntes para la Revolución del 29, más conocido como Memorias (1840), así como de manifiestos, proclamas, comunicaciones, arengas y decretos que revelan al estadista y al escritor ilustrado. Con los años, se convirtió en la máxima figura histórica de Centroamérica, específicamente a partir de las Reformas Liberales que celebraron su gesta unionista y desarrollaron una "estatuaria" alrededor de su personalidad. La máxima condecoración que otorga el Estado de Honduras, fue creada el 1 de marzo de 1941 en el gobierno de Tiburcio Carías en homenaje al General Morazán, denominada "Orden de la Gran Cruz de Oro Francisco Morazán”. Cfr. "Honduras: Order of Francisco Morazán”, En: www.medals_org-uk-honduras-images-honduras001_jpg.htm, 2001, p. 1.

${ }^{2}$ Véase: Cfr. Hobsbawm, Eric y Ranger, Terence, The Invention of Tradition, Cambridge, University Press, 1983, p. 29. 


\section{La "Invención de la tradición" del "Panteón de los héroes nacionales" mediante la estatuaria cívica, la exaltación de la figura de Morazán y los imaginarios de nación morazánicos en Honduras y Centroamerica}

Con relación al proceso de creación del imaginario de Morazán como uno de los principales símbolos de la identidad nacional en Honduras y Centroamérica, hay que señalar que uno de los espacios en los que tuvo mayor conquista la Reforma Liberal en su proceso de conformación nacional fue en el campo de la "estatuaria cívica".

En efecto, en el tránsito del siglo XIX al XX, la estatuaria cívica se convirtió en el mundo occidental en un medio idóneo para representar y evocar la memoria arquetípica de los héroes nacionales ${ }^{3}$.

Por su parte, Jacques Le Goff, en su estudio El orden de la memoria. El tiempo como imaginario, sugiere que las estatuas de los héroes que se instalaron en los Parques y plazas de las ciudades de Europa y América Latina "visualizan" las glorias nacionales. La estatuaria e imaginería cívica, conceptuada como "material de la memoria", manifiesta de esa forma un carácter pedagógico y simbólico, que enlaza el pasado con el presente y lo proyecta hacia el futuro ${ }^{4}$.

Asimismo, Le Goff añade que los monumentos (en latín monumentum), son obras de carácter público que se convierten en puntos de "referencialidad" espacial y de emociones emblemáticas ante los espectadores.

En fin, el monumento o estatua es todo lo que puede hacer volver al pasado, perpetuar el recuerdo, vale decir los acontecimientos conmemorativos de las naciones.

En el caso de Centroamérica, Patricia Fumero ha estudiado la ritualización de la estatua del costarricense Juan Santamaría en el proceso de construcción de la nación en ese país y advierte que "[...] la estatuaria civica se transforma en un referente espacial y del poder al brindar una serie de valores que permiten la consagración del poder que los grupos dominantes desean proyectar"

Con relación a Honduras y América Latina en general, durante la era liberal de finales del siglo XIX, los Estados se dieron a la tarea de acometer la instalación en sus

${ }^{3}$ Cfr. Brenes Tencio, Guillermo, "La estatuaria cívica: el caso de Costa Rica siglos XIX y XX", En: Revista Ciencias Sociales, San José de Costa Rica, Vol. VII, Número 96, Junio del 2002, pp. 9-22.

${ }^{4}$ Le Goff, Jacques, El orden de la memoria. El tiempo como imaginario, Barcelona, Editorial Paidós, 1991, p. 227.

${ }^{5}$ Fumero, Patricia, "La celebración del Santo de la Patria: La develización de la estatua al héroe nacional costarricense, Juan Santamaría, el 15 de septiembre de 1891", En: Enríquez Solano, Francisco (Compilador), Fin de siglo XIX e identidad nacional en México y Centroamérica, Alajuela, Museo Histórico Cultural Juan Santamaría, 2000, pp. 405-406. 
principales espacios públicos de toda una estatuaria cívica, no solamente para el amueblamiento urbano y estético, sino con dos fines:

- Primero, mediante distintas manifestaciones escultóricas (estatuas, bustos), se construyó en el imaginario un vínculo asociado a "Hombres ilustres" (Héroes, próceres y Beneméritos) con los valores y aspiraciones colectivas de la nación.

- Segundo, entre los ciudadanos y las virtudes cívicas representadas, la representación se convirtió en una máquina de fabricar respeto, legitimidad y sumisión.

En el caso de Honduras pues, es en esta época de la Reforma Liberal que se institucionalizó el "Panteón de los héroes nacionales". Los reformadores tomaron como arquetipo de "héroe" la figura del general Francisco Morazán. De hecho, ellos eran conscientes, especialmente Ramón Rosa, de que la Reforma era una empresa que encarnaba la continuidad del proyecto federalista; así, concebían que la epopeya morazánica -interrumpida con el triunfo de los conservadores en 1839-renacía con las revoluciones liberales acaecidas a partir del último cuarto del siglo XIX; en otras palabras, "imaginaban" que el proyecto inacabado de la Federación -es decir, la consolidación de la nación-, sería consumado mediante la labor transformadora de las Reformas Liberales.

Fue así que en Centroamérica empezó la tarea de construir un "Panteón de los Héroes nacionales" en la región. El país que comenzó el proceso de lo que podríamos denominar la "heroización" de la figura de Morazán fue justamente El Salvador, cuando su gobierno autorizó la repatriación de los restos del General unionista. Morazán había sido fusilado en San José de Costa Rica el 15 de setiembre de 1842. En Costa Rica como en los demás países centroamericanos, su muerte fue celebrada como "la caída del tirano". Pero hacia 1848, durante el gobierno de Doroteo Vasconcelos, se decidió exhumar los restos de Morazán y repatriarlos a El Salvador, "teniendo en consideración, según argumentaba ese gobierno: 1. Que es un deber de los Gobiernos civilizados honrar la memoria de los varones célebres; 2. Que el general Francisco Morazán legó sus restos mortales al Estado de El Salvador; 3. Que el Gobierno de Costa Rica, fiel amigo y aliado del de aquel país hermano, desea darle claros testimonios de distinguida consideración y aprecio"6. La repatriación de sus restos puede ser entendida como un intento de unir gobiernos liberales al construir una contra-memoria o una historiografía capaz de enfrentarse al discurso conservador hegemónico a escala de América Central. Al enaltecer la figura de Morazán como símbolo federador, se quería fortalecer los vínculos entre los gobiernos liberales.

${ }^{6}$ Véase: Lacaze, Catherine, Acercamiento al proceso de heroización de Francisco Morazán en la América Central (1848, 1892, 1942), Toulouse, Universidad de Toulouse, 2013. p. 
Sin embargo, la reificación del "Panteón morazánico" en El Salvador tuvo que esperar otro contexto de "esperanza liberal" con la llegada al poder de Gerardo Barrios, quien había luchado al lado de Morazán, para que se organizara la inhumación solemne de sus restos en el "Cementerio General" de San Salvador, posteriormente denominado "Cementerio de los Ilustres, donde hoy yace inmortal el general Morazán. Las celebraciones se desarrollaron entre los días 14 y 17 de setiembre de 1858 y Barrios quiso escenificar la estrecha vinculación entre las dimensiones cívica, religiosa y militar con el fin de hacer de Morazán la encarnación de un ideal sagrado por el cual había que sacrificarse y de esta manera legitimar su propio proyecto de reconstrucción de la unión centroamericana.

El segundo homenaje que El Salvador tributó a la "heroización" de la figura de Morazán fue la fabricación de la primera estatua del general en la región centroamericana, escultura que encomendó a los artistas suizo-italianos Franciisco y Lorenzo Durini el gobierno reformista de Rafael Zaldívar, obra inaugurada el 15 de septiembre de 1882, y en la que el orador hondureño Álvaro Contreras -suegro de Rubén Darío- pronunció su famoso discurso en donde plasmó una de las frases más memorables dedicadas al Héroe de la Trinidad: "Suprimid el genio de Morazán, y habréis aniquilado el alma de Centro América”.

En el caso de Honduras, por esa misma época se instala en 1876 el gobierno de Marco Aurelio Soto y Ramón Rosa, aliados del régimen liberal de Zaldívar, y el Estado empieza a desempeñar un papel fundamental en el proceso de "heroización", que a la vez se insertaba dentro del proyecto de inventar la nación.

De esa forma, el régimen de Soto mandó fabricar en Europa una serie de estatuas de los héroes y próceres destacados de la etapa independentista, así como de otros personajes sobresalientes en el ámbito cultural e intelectual de los primeros años de la configuración del Estado-nación hondureño. La elaboración de las estatuas quedó aprobada según un Decreto del 27 de agosto de 1882. A tal efecto, se suscribió una contrata entre Ramón Rosa, representante del gobierno, y el ingeniero de origen italiano Francisco Durini el 29 de julio del mismo año. La estatua encomendada más importante fue desde luego la de Francisco Morazán, que fue alzada en ceremonia especial el día 30 de noviembre de 1883 en el sitio que anteriormente se denominaba como "Plaza de Armas" en el mero corazón de Tegucigalpa, la nueva capital. Con la erección del monumento al héroe unionista, el parque se conoció desde entonces como "Plaza Morazán" hasta mediados del siglo XX, tiempo desde el cual se empezó a llamar simplemente como "Parque Central"7.

Curiosamente, durante el siglo XX, apareció una leyenda según la cual, dicha estatua no era la de Morazán, sino -de acuerdo a algunos detractores-, la del Mariscal francés

\footnotetext{
${ }^{7}$ Para más información sobre la contrata emitida por el gobierno de Marco Aurelio Soto para construir las estatuas de Morazán y Valle, así como los bustos de Cabañas y el Padre Reyes, puede verse: "Diario Oficial La Gaceta", Contrata celebrada por el Supremo Gobierno para que se coloquen en esta capital las estatuas de Francisco Morazán, y de José Cecilio del Valle, y los bustos de José Trinidad Cabañas, y de José Trinidad Reyes, Tegucigalpa, Suplemento al Número 174, 27 de agosto de 1882. (ANH).
} 
Ney; de hecho, el colombiano Gabriel García Márquez, en su discurso de aceptación del Premio Nobel en 1982, señaló -haciéndose eco de la leyenda-, que “[...] el monumento al general Francisco Morazán, erigido en la plaza mayor de Tegucigalpa, es en realidad una estatua del mariscal Ney comprada en París en un depósito de esculturas usadas". Del mismo modo, el uruguayo Eduardo Galeano, en su ya mítico libro Las venas abiertas de América Latina, tomando como fuente a García Márquez, repite la misma historia de la supuesta falsa identidad de la estatua al héroe unionista?

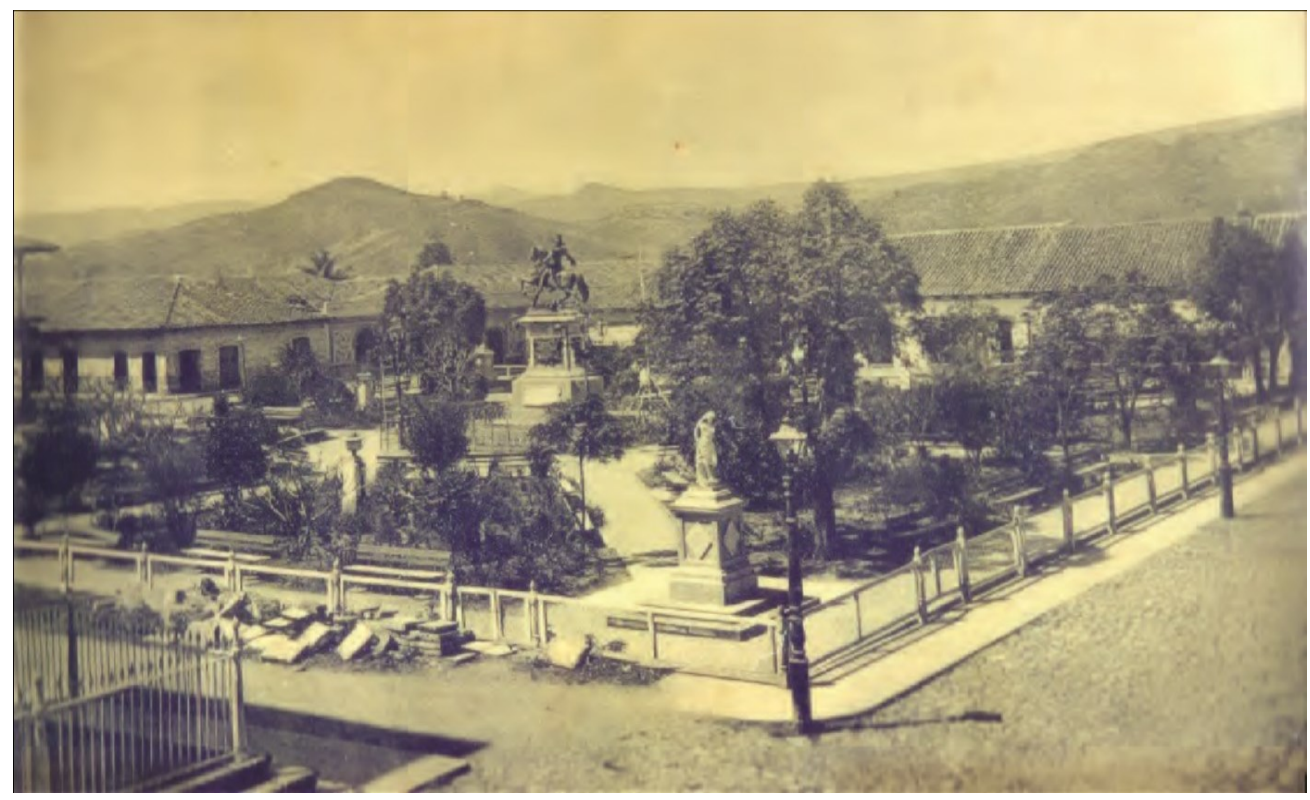

Fotografía de 1882 de la estatua de Francisco Morazán recién instalada en ese entonces en la "Plaza Morazán”, hoy Parque Central, (Foto original del fotógrafo cubano T. Aguirre, Archivo Jorge Amaya).

Lo cierto es que la estatua referida sí es la del general Morazán, como demostró en un documentado estudio el diplomático hondureño Rafael Leiva Vivas; él encontró en París documentación que acreditaba la autenticidad de la estatua, relatando que el contratista, Francisco Durini, a su vez, había encargado la elaboración de la estatua al escultor francés Leopold Morice, el cual fundió la pieza en los talleres de "Thiebaut Fréres". La fabricación quedó registrada en el Archivo Nacional de París -según el documento- en la sección "Estatuas Ejecutadas para el Extranjero", con la signatura F12-5283 ${ }^{10}$.

\footnotetext{
${ }^{8}$ Conferencia de Gabriel García Márquez, al recibir en Estocolmo el Premio Nobel de Literatura en 1982.

${ }^{9}$ Galeano, Eduardo, Las venas abiertas de América Latina, Madrid, Siglo XXI Editores, $3^{\text {a }}$ edición, 1982, p. 432 .

${ }^{10}$ Véase: Leiva Vivas, Rafael, Francisco Morazán y sus relaciones con Francia, Tegucigalpa,
}

Editorial Universitaria, Colección Homenajes, N 3, 1ª edición, 1988, pp. 136

(C) Universidad Tecnológica de El Salvador 
Desde entonces, Morazán se convirtió en el prócer hondureño más "ritualizado" en los espacios públicos de las principales ciudades del país, pues existen estatuas o bustos suyos en otras ciudades como San Pedro Sula, La Ceiba, Amapala, Choluteca, Santa Bárbara, Santa Rosa de Copán y Trujillo entre otras; se podría decir a la vez que es el centroamericano que ostenta mayor cantidad de efigies alrededor del mundo, ya que existen iconografías de él en todas las capitales de Centroamérica, así como en otras ciudades del resto del mundo como Nueva Orleáns, Lima, Caracas, Santiago de Chile, México DF, Buenos Aires y Madrid ${ }^{11}$.

Otro elemento que contribuyó a forjar el imaginario de Morazán como principal fuente de identidad en Honduras fue la reconstrucción de su vida como vehículo de imitación ciudadana a través de la redacción y difusión de su Historia y su biografia. De hecho, el mismo Ramón Rosa escribió una obra -probablemente la primera biografía escrita en el país- sobre la vida del héroe, titulada Historia del Benemérito General Don Francisco Morazán ${ }^{12}$.

Desde entonces, historiadores, poetas, narradores, teatristas, pintores y casi todos los intelectuales del país han escrito o publicado obras alusivas a la historia del General Morazán. En este sentido, posiblemente Morazán sea el personaje de la Historia hondureña más estudiado en el país y por extensión en la región centroamericana ${ }^{13}$.

Igualmente, desde la Reforma Liberal Morazán quedó firmemente vinculado con la principal "Fiesta cívica" en el calendario de efemérides hondureña: "La Celebración de la Independencia del 15 de Septiembre", pues entre finales del siglo XIX y hasta la década de los años 60 del siglo XX, los desfiles del "15 de Septiembre" solían culminar en la rotonda de la estatua del General en el Parque Central.

Finalmente, Morazán ha sido un poderoso instrumento de identificación nacional, de modo que su nombre se ha internalizado en la conciencia colectiva con el fin de nombrar espacios, lugares, instituciones, negocios, barrios, escuelas y hasta instancias de la vida cotidiana como estadios, cafeterías, hoteles y cantinas; así, existen en toda Honduras espacios con sus nombres: en nombres de departamentos (Al igual que en El Salvador): también hay un "Estadio Morazán" en San Pedro Sula, la "Represa Francisco Morazán" en El Cajón, el "Bulevar Morazán" en Tegucigalpa, el "Barrio Morazán" en Tegucigalpa, "Universidad Pedagógica Nacional Francisco Morazán UPNFM" en la misma capital, una academia de policía, la "Academia Nacional de Policía Francisco Morazán"; también su efigie se estampó en monedas, sellos postales, carteles para las escuelas, etcétera. De hecho, en San José de Costa Rica hay también una "Cantina Morazán". Para agregar a esta parafernalia, la máxima presea que otorga

\footnotetext{
${ }^{11}$ Acerca de la representación de Morazán en estatuas y otros medios consúltese: Jerez Alvarado, Rafael, Monumentos y elogios al General Morazán, Tegucigalpa, 1986, S/N, p. 141.

12 Rosa, Ramón, Historia del Benemérito General Don Francisco Morazán, Tegucigalpa, 1971.

${ }^{13}$ Sobre este punto vale revisar: Umaña, Helen, Morazán en la literatura hondureña, San Pedro Sula, Centro Editorial, 1995.
} 
el Estado de Honduras se denomina "Orden de Francisco Morazán". Se podría decir que en el caso de la cultura e identidad hondureña ha habido un fuerte proceso de "morazanización" de su identidad.

De alguna manera, la consecuencia de este proceso de "heroización" y "deificación" de la figura de Morazán contribuyó a forjar una historiografía de corte liberal. La historiografía de la triunfante Reforma Liberal ubicó el origen de la "Historia Patria" en la Independencia contra España de 1821, y Morazán se convirtió en una especie de "Pater Patriae" y en el inmaculado gestor de los ideales liberales y reformadores. En contraposición, esta historiografía liberal satanizó a los personajes históricos opositores o enemigos de Morazán ligados al conservadurismo, como por ejemplo Rafael Carrera, Francisco Ferrera, José Santos Guardiola o José María Medina, quienes fueron difamados y desprestigiados en los libros de texto de historia, o en el mayor de los casos condenados a un limbo histórico.

Esta visión historiográfica liberal que exaltó a Morazán y ensombreció a los conservadores condujo a la difusión de discursos nacionalistas liberales, y por ende a la constitución de una "Historia maniquea" entre buenos (los liberales) y malos (los conservadores).

Desde 1876, esta visión histórica fue también la que se empezó a desplegar en las escuelas, colegios y universidades del país, convirtiéndose entonces en la que es denominada por algunos historiadores como "Historia didáctica", nombrada también por el historiador mexicano Luís González como "Historia de bronce" o "Historia reverencial"14.

Esta forma de hacer historia aún divide a los actores sociales que forman parte en los hechos históricos entre buenos y malos. Con inusitada frecuencia en un extremo aparecerán los héroes - sin mencionar sus errores - y en el otro se ubicarán los traidores, los vende-patrias, sin que se les reconozca cualidad alguna. Esta historia es la preferida por las instituciones gubernamentales, pues configura a los "grandes hombres" como personajes con quienes es fácil identificarse debido a su presentación como seres casi únicos, extraordinarios.

En suma, creemos que la figura de Morazán ha sido un instrumento discursivo de identidad nacional por antonomasia en Honduras. Es posible que con los brutales acontecimientos generados a partir del Golpe de Estado de junio del 2009 y la toma de conciencia nacionalista entre la intelligentsia progresista y de izquierda, la visión de Morazán tienda a ser revisitada desde un enfoque que rescate a un Morazán más revolucionario y elevado a una estatura continental, en la línea de Simón Bolívar.

${ }^{14}$ Véase: González, Luís, Viaje por la Historia de México, México DF, CONACULTA, 2009. 
Sin duda, a pesar de esa perspectiva maniquea, es difícil negar que Morazán sea quizás el personaje de la Historia hondureña con mayor dimensión continental e incluso universal.

Finalmente, es importante exponer que la figura de Morazán ha sido tan poderosa en la construcción de imaginarios de identidad nacional, que incluso ha sido tomado como bandera de lucha por ideologías e instituciones tan disímiles como los militares de extrema derecha fascista, por el Partido Liberal, por grupos guerrilleros de izquierda en los años 80 como el legendario Frente Morazanista de Liberación Nacional (FMLN), y hoy en día por el Frente Nacional de Resistencia Popular (FNRP).

Toda esta parafernalia sustentada en la proliferación de la estatuaria respondía al esfuerzo centralizador que el régimen de Soto buscaba proporcionar al Estado-nación hondureño. En todo caso, lo cierto es que la Reforma aportó las bases del panteón de los héroes nacionales, encabezado por Francisco Morazán, Dionisio de Herrera, José Trinidad Cabañas y José Cecilio del Valle. Todos esos símbolos han trascendido hasta nuestros días, transmitidos de generación en generación a través del sistema educativo y más recientemente mediante los medios masivos de comunicación. También, el carácter épico o legendario quedó signado por la "ritualización" específica que se hizo de cada una de esas "imágenes"; así, por ejemplo, Morazán, Herrera y Cabañas quedaron proclamados como los "héroes" unionistas, defensores de la República Federal; Valle como el intelectual ilustrado, el "sabio" más glorioso que ha parido Honduras y al Padre Reyes se le honró como el "protector" de la cultura nacional y de la educación ${ }^{15}$.

En resumen, La Reforma Liberal hondureña constituyó un acontecimiento de trascendental importancia en la historia del país y sentó las bases para una modificación sustancial de las viejas estructuras heredadas del período colonial; asimismo, ejerció una influencia profunda en el ulterior desarrollo de la historia nacional. Con ella, se cimentaron los fundamentos que dieron forma más estable y centralizada al Estado-nación hondureño, inventando gran parte de los símbolos y elementos identitarios que configuran los imaginarios de nación en Honduras, especialmente a partir de la figura colosal del general Francisco Morazán.

\section{3) El legado de Francisco Morazán a la Centroamérica actual}

Este sintético recorrido del homenaje y reconocimiento oficial que han construido los países centroamericanos al proceso de "heroización" del general Francisco Morazán a través de todas esas instancias o imaginarios de nación, nos comprometen a seguir difundiendo su colosal legado político, cívico, social, educativo, cultural e histórico,

\footnotetext{
${ }^{15}$ Sobre este asunto puede consultarse entre otros: Barahona, Marvin, Evolución histórica de la identidad nacional, Tegucigalpa, Editorial Guaymuras, Colección Códices de Ciencias Sociales, 1990, pp. 243 y 244 .
} 


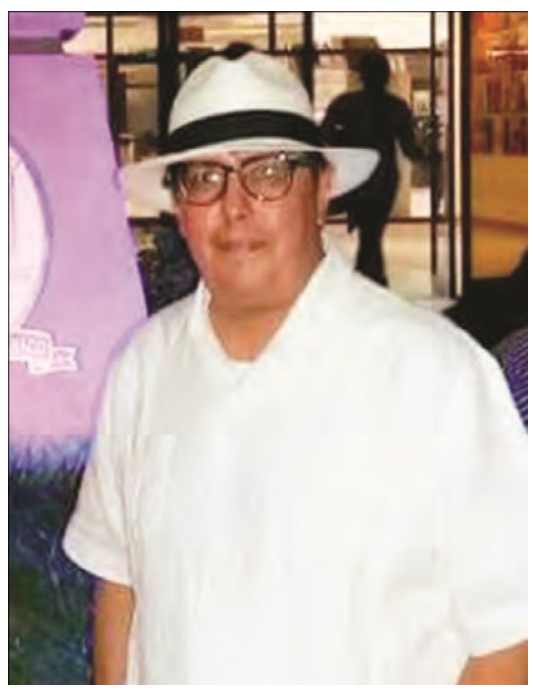

Jorge Alberto Amaya Banegas

el cual es invaluable tanto para nuestra región como para el resto de América Latina, ideales por los cuales sacrificó su propia vida.

En general, creemos que el principal legado político del general la región centroamericana fue habernos heredado la noción de las "garantías individuales", es decir, el reconocimiento que todos los individuos tienen una serie de derechos inalienables, como el derecho a ser ciudadanos, a la libertad, el derecho a la vida, el derecho a elegir y ser electos a cargos públicos, y el derecho a la propiedad, a la libertad de conciencia. Asimismo, Morazán nos legó el paradigma de que el Estado debe instituirse a partir de la creación de una "Carta Magna" promulgada por el "soberano" y sus representantes.

En cuanto al legado educativo, Morazán introdujo el modelo de educación laica heredado de la Revolución Francesa y del "Código Napoleónico", que reconoce que la educación debe estar a cargo del Estado, y que debe ser basada en una pedagogía laica, pública y gratuita, además de que debe aspirar a ser una educación "liberadora" y de carácter popular, de ahí que se decantara por introducir un modelo pedagógico innovador y revolucionario para aquella época, a través del "modelo lancasteriano", que consistía en la utilización de estudiantes monitores que estuvieran avanzados en el curso, para que ellos enseñaran a los alumnos menos aventajados, con el fin de suplir la falta de maestros y de recursos económicos.

En cuanto al legado social, Morazán introdujo la reforma religiosa de la libertad de cultos y de religión, así como la libertad de expresión y la libertad de conciencia, plasmando derechos revolucionarios para aquellos años en la América Latina. En el 
caso de Honduras, introdujo la primera imprenta en Tegucigalpa en 1829, siendo el germen de la vida literaria, bibliográfica y periodística en el país.

En materia económica, Morazán impulsó el derecho a la libertad de comercio, borrando las trabas y monopolios que controlaron el comercio en la época colonial, y de esa manera impulsar una revolución democrática burguesa y la Modernidad.

Finalmente, en cuanto al legado cívico, Morazán nos heredó el máximo ideal a los pueblos centroamericanos, cual es la idea de la "Unión" como motor de la integración y de la formación de un Estado fuerte, respetado internacionalmente y que sustente a partir de la enormidad de sus recursos naturales la prosperidad de las naciones centroamericanas.

Todas estas medidas y anhelos han sido parcialmente enfrentadas a lo largo de la historia por los sectores conservadores o pudientes de la región, de modo que muchas de esas utopías y sueños son aún vigentes en Honduras y Centroamérica, por lo tanto, en esta fecha en que se instala en la Universidad de El Salvador (UES) la "Plaza de la Integración Centroamericana" y en que se develiza un busto donado por nuestra UPNFM a la UES y a la hermana República de El Salvador en ratificación de fraternidad morazánica, reiteramos que como Universidad de vocación morazanista, la UPNFM siempre aspirará y luchará por cumplir el sueño de alcanzar la Unión y construir Patrias con justicia social y con educación popular para todas y todos los centroamericanos.

\section{Referentes bibliográficos}

Barahona, Marvin. Evolución histórica de la identidad nacional, Tegucigalpa, Editorial Guaymuras, Colección Códices de Ciencias Sociales, pp. 243 y 244. 1990

Brenes Tencio, Guillermo. "La estatuaria cívica: el caso de Costa Rica siglos XIX y XX”, En: Revista Ciencias Sociales, San José de Costa Rica, Vol. VII, Número 96, Junio del 2002, pp. 9-22.

Conferencia de Gabriel García Márquez al recibir en Estocolmo el Premio Nobel de Literatura en 1982.

Diario Oficial La Gaceta. Contrata celebrada por el Supremo Gobierno para que se coloquen en esta capital las estatuas de Francisco Morazán, y de José Cecilio del Valle, y los bustos de José Trinidad Cabañas, y de José Trinidad Reyes, Tegucigalpa, Suplemento al Número 174, 27 de agosto de 1882. (ANH). 1882.

Fumero, Patricia. "La celebración del Santo de la Patria: La develización de la estatua al héroe nacional costarricense, Juan Santamaría, el 15 de septiembre de 1891", En: Enríquez Solano, Francisco (Compilador), Fin de siglo XIX e identidad 
nacional en México y Centroamérica, Alajuela, Museo Histórico Cultural Juan Santamaría, 2000, pp. 405-406.

Galeano, Eduardo. Las venas abiertas de América Latina, Madrid, Siglo XXI Editores,

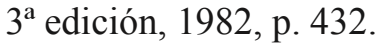

González, Luís, Viaje por la Historia de México, México DF, CONACULTA, 2009. Hobsbawm, Eric y Ranger, Terence. The Invention of Tradition, Cambridge, University Press, 1983, p. 29.

Honduras: Order of Francisco Morazán". En: www.medals_org-uk-hondurasimageshonduras001_jpg.htm, p. 1. 2001

Jerez Alvarado, Rafael. Monumentos y elogios al General Morazán, Tegucigalpa, S/N, p. 141.1986.

Lacaze, Catherine. Acercamiento al proceso de heroización de Francisco Morazán en la América Central (1848, 1892, 1942), Toulouse, Universidad de Toulouse, 2013. p.

Le Goff, Jacques. El orden de la memoria. El tiempo como imaginario, Barcelona, Editorial Paidós, 1991, p. 227.

Leiva Vivas, Rafael. Francisco Morazán y sus relaciones con Francia, Tegucigalpa, Editorial Universitaria, Colección Homenajes, $\mathrm{N}^{\mathrm{o}} 3$ 3 $^{\mathrm{a}}$ edición, pp. 136. 1988

Rosa, Ramón. Historia del Benemérito General Don Francisco Morazán, Tegucigalpa, 1971.

Umaña, Helen. Morazán en la literatura hondureña, San Pedro Sula, Centro Editorial, 1995. 


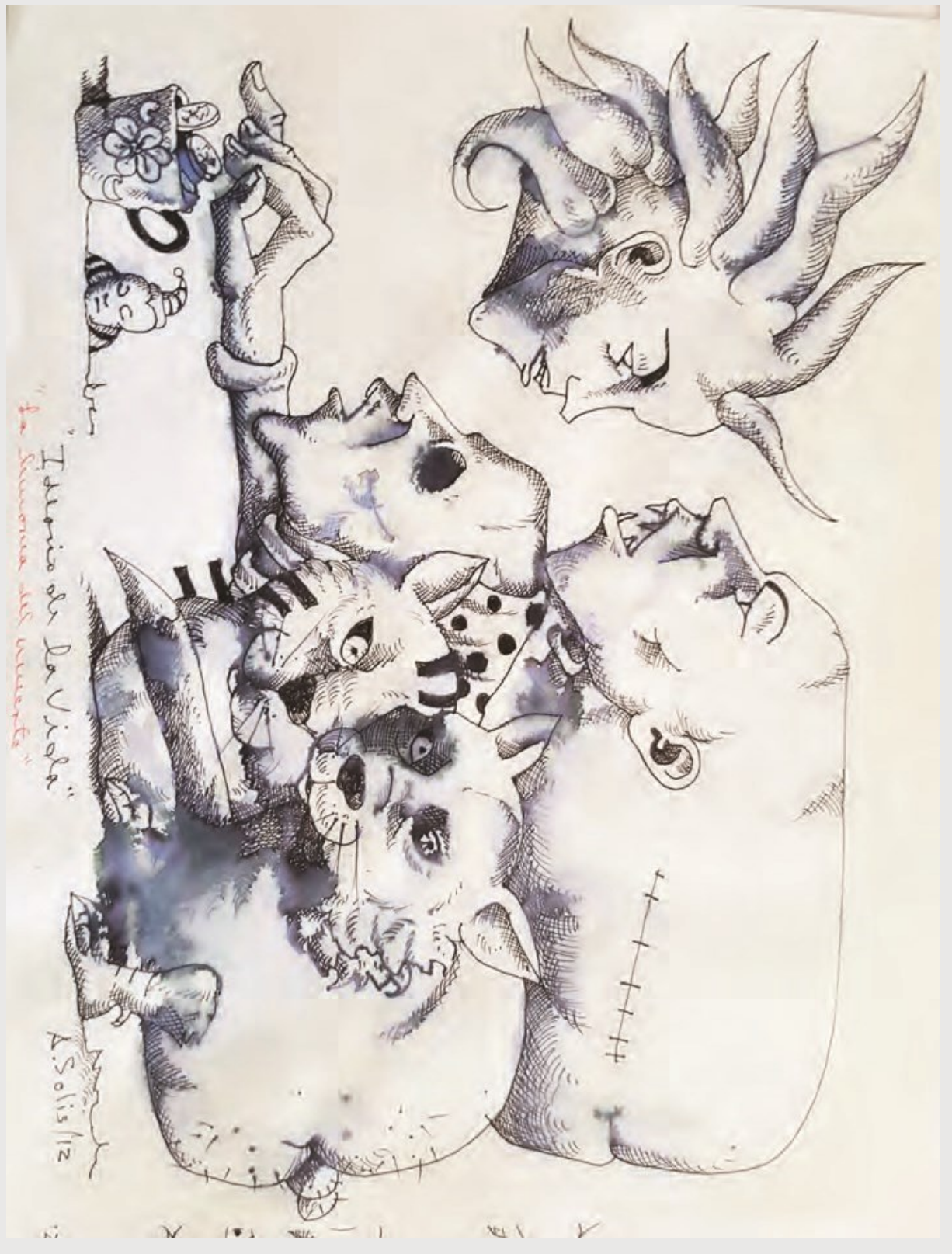

Armando Solis 